\title{
Family Presence During Resuscitation: Adaptation and Validation into Spanish of the Family Presence Risk-Benefit Scale and the Self-Confidence Scale Instrument
}

\section{Eva de Mingo-Fernández ( $\nabla$ evamariade.mingo@urv.cat)}

Consorci Sanitari del Garraf https://orcid.org/0000-0001-9015-7578

Ángel Belzunegui-Eraso

Universitat Rovira I Virgili

María Jiménez-Herrera

Universitat Rovira i Virgili Escola Universitaria d'Infermeria

\section{Research article}

Keywords: Family witnessed resuscitation, Ethic PCR, Family Presence during resuscitation, Staff Opinion

Posted Date: January 19th, 2021

DOI: https://doi.org/10.21203/rs.3.rs-31012/v3

License: (c) (1) This work is licensed under a Creative Commons Attribution 4.0 International License. Read Full License

Version of Record: A version of this preprint was published on March 12th, 2021. See the published version at https://doi.org/10.1186/s12913-021-06180-2. 


\section{Abstract}

\section{BACKGROUND}

Family Presence during Cardiopulmonary Resuscitation has been studied both to identify the opinions of health professionals, patients, and family members, and to identify benefits and barriers, as well as to design protocols for its implementation. R.Twibell and her team designed an instrument that measured nurses' perceptions of Risks-Benefits and Self-Confidence regarding Family Presence during Resuscitation. There are few studies in Spain on this practice.

\section{Methods}

The aim is to adapt and validate into Spanish the Family Presence Risk-Benefit scale and Family Presence Self-Confidence scale instrument. For this purpose, this instrument was translated crossculturally, and administered in paper and online version. Statistical tests were carried out for the validity of the questionnaire. 541 healthcare professionals were invited to respond. The results were analyzed by the same statistical procedures as in the original scale. Ethical approvals and research permissions were obtained according to national standards.

\section{Results}

237 healthcare professionals (43.8\%) answered the survey (69\% women), of whom 167 were nurses. Validation of instruments: Cronbach's a in Family Presence Risk-Benefit scale was 0.94 . Cronbach's a in Family Presence Self-Confidence scale was 0.96. Factor Analysis Kaiser, Meyer and Olkin (KMO) was greater than 0.9. The correlation between the two measured scales, is significant and has a moderate intensity of the relationship $(r=0.65$ and $a<0.001)$.

A lower predisposition to Family Presence during Cardiopulmonary Resuscitation is observed, but the pure detractors are only $12 \%$. Doctors are more reluctant than nurses.

\section{Conclusions}

The psychometric properties of the questionnaire in Spanish indicate high validity and reliability. RiskBenefit perception and Self-Confidence are related to the healthcare professionals who consider the Family Presence to be beneficial. More studies in different contexts are necessary to confirm the psychometric results and validity of this instrument in Spanish.

\section{Background}

The World Health Organization (WHO) concept of health allows for a holistic view of the human being, with attention focused on the person, by including the family and the communities in the center of the health system, since the individual develops within the family and the family becomes the first patient support system (1). 
Family Presence During Resuscitation (FPDR) can be defined as the presence of one or more family members in the space where cardiopulmonary resuscitation (CPR) is being performed and that they are able to maintain visual or physical contact with the patient and healthcare team (1).

In 1982, at the Foote Hospital in Michigan in the United States, the protocols of the time, which did not allow FPDR, were challenged by the request of two families to be present during CPR, generating a debate about the right to be at the side of their relatives ${ }^{(3)}$.

Family Presence during Resuscitation (FPDR) is controversial. From the health professionals' point of view, some authors point out, as general arguments in favor, that it offers the opportunity to give emotional support to the patient and to be by the side of the loved one, reducing at the same time the anxiety of the relatives. It also allows to follow the events at all times, which facilitates making quick and consensual decisions in situ ${ }^{(4,5)}$, and enabling a better process of grief (2).

The arguments to the contrary focus on several aspects, such as that the medical team feels evaluated and analyzed, thus causing them discomfort and pressure (3-6); the frequency with which lack of knowledge and misinterpretation of procedures by family members give rise to traumas, complaints and fears of a possible interruption of proceedings; and also the limited physical space and legal vacuum, since there are no guidelines in this regard $(5,7,8)$. Relatives who have witnessed CPR think that it is beneficial for the patient and families, and this opinion is not conditioned by age, education or income, nor by the last will and testament (9). Other determining factors for the acceptance of FPDR are of cultural and religious nature, varying the percentages of acceptance of FPDR when the studies come from countries with different cultural and religious traditions (10-16).

The European Resuscitation Council (ERC), a component of the International Liaison Committee on Resuscitation (ILCOR), in its 2015 ethical recommendations, states that the medical team should offer selected family members the opportunity to be present during the resuscitation of a loved one, the health team should be sensitive to FPDR, assigning a member of the team (if possible) to inform, support and give comfort to the family member present ${ }^{(20)}$. Additionally, the European Federation of Critical Care Nursing associations (EfCCNa) and the European Nursing Organizations support the FPDR $(17,18)$.

From an ethical point of view, hospital policies restricting FPDR should be rectified, and new protocols should be developed to enable admitting the family to these procedures, as the principle of patient's autonomy supports this.

The primary aim of our study is to adapt and validate the scale of Twibell et al, since we found that we were not able to use it in our language. This study is necessary to obtain a reliable tool in Spanish, which would facilitate further studies on FPDR. The secondary aim was to know the opinions of health professionals (both medical and nursing staff) who work in different health services of the Consorci Sanitari del Garraf (CSG) of Barcelona, Spain, such as the Intensive Care Unit (ICU), Emergencies (ER), Dialysis, Social Healthcare (SH), Hospitalization facilities, etc., and thus objectify the opinions and 
preferences of the doctors and nurses carrying out the pre- and intrahospital services. To this end, the three-scales from the study of Twibell et al. (2008) are replicated: Family Presence Risk-Benefit (FPRB), Family Presence Self-Confidence (FPSC) (19) and also, a sociodemographic questionnaire. These indices measure the perceptions of doctors and nurses about the risks-benefits and self-confidence that the presence of the family entails in CPR. The transcultural translation of the instrument was performed, including the physicians in it, and the results obtained in the original study were compared with those obtained in the Garraf region (Barcelona). There are few studies in Spain on this practice and we translated this instrument so that further studies on FPDR can be carried out.

\section{Methods}

Ethical approvals and research permissions were obtained according to national standards, guaranteeing the anonymity of the respondents. The study was approved by the institutional review board of the Consorci Sanitari del Garraf, and by the clinical research Ethic Committee of the Fundació Unió Catalana Hospitals with code CEIC 15/31.

The questionnaires elaborated by Twibell et al. (2008) on FPRB-FPSC were selected because they provide high level of internal consistency and construct validity, following maximum likelihood exploratory factor analysis with varimax rotation. These scales are a valuable method to evaluate professionals' perceptions of the risks, benefits, and self-confidence to manage FPDR. They consist of 3 questionnaires, a socio-demographic one, another one that evaluates risk-benefit (FPRB) and the last one that evaluates self-confidence (FPSC). The FPRB scale requires participants to rate their agreement with 22 items using a five-point Likert scale which ranges from strongly disagree (1) to strongly agree (5). A higher score indicates a greater level of the benefit perceived from FPDR. Only one factor was identified, accounting for $53 \%$ of variance in nurses' perceptions of risks and benefits of FP. Factor loadings ranged from $0.890-$ 0.0498 and internal consistency was Cronbach's alfa of 0.96 .

The FPSC scale also requires participants to rate their agreement with 17 questions using a five-point Likert scale, which ranges from not at all confident (1) to very confident (5). A higher score indicates a greater level of self-confidence in managing FPDR. Also, only one factor was identified for the 17 items, accounting for $52 \%$ of respondents' perceptions. The FPSC factor loadings ranged from $0.553-0.825$ and internal consistency was Cronbach's alpha of 0.95 .

Some items of the sociodemographic variables have been changed (Table 1) to fit the ethnic, professional, and educational profile of our country. Doctors were included to obtain a more generalized view of the subject. Initially, the questionnaire was applied to nurses, but other studies such as those of MC Lean (24) and Chapman (25) included doctors in them, which allowed to make comparisons between the two health groups. 


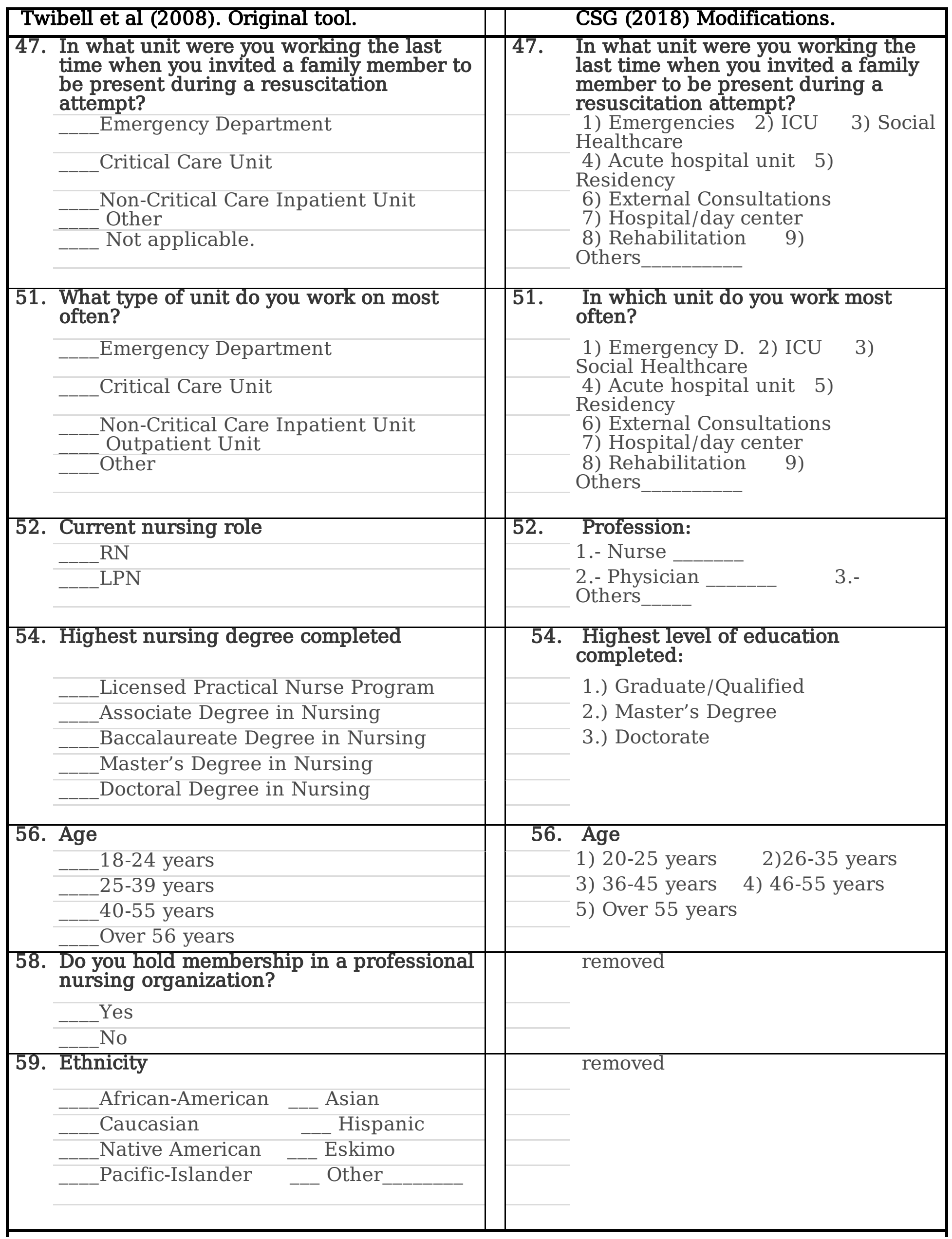


The inclusion criteria was to be a doctor or a nurse working in the CSG. A convenience sample was created. It was formed of 541 CSG health professionals, of whom 197 are doctors and 344 nurses. They were invited to respond anonymously to this survey. The invitation to participate in the survey was sent by the main researcher, via corporate mail in a direct message with a link to Google Forms, from September $1^{\text {st }}, 2018$ to October $31^{\text {st }}, 2018$ and from May $1^{\text {st }}, 2019$ to June $30^{\text {th }}, 2019$. The respondents were given the option to answer to the survey on paper or online, via Google forms. To collect the paper surveys, cardboard boxes were provided, notifying the day of collection so that the anonymity of the respondents could be respected. To calculate the margin of error, a $95 \%$ confidence level was selected, with simple random sampling.

\section{1.- Transcultural translation and validation of the instrument.}

The survey by Twibell et al. (2008) was selected for transcultural translation. The methodology used for the cross-cultural adaptation of questionnaires for use in health research was the one proposed by Sousa and Rojjanasrirat (20). Two native Spanish translators with fluent English translated it into Spanish and two native English translators translated it back into English so that the questions were similar and had the same meaning as in the original survey. In an initial pilot study, 25 surveys were completed to determine if the healthcare professionals understood the questions; comprehension problems arose with 3 of them. A Delphi group was convened with research, resuscitation, and ethics experts, and the 3 questions were resolved so that the final questionnaire could be developed.

To validate that the items measured the same underlying dimension, factorial analysis was performed using the maximum likelihood method, as in Twibell et al. (2008), with all of the variables and not excluding them from the analysis due to the existence of low item-total correlations.

Next, the validity of the indices of the instrument caused by transcultural translation was questioned, calculating its reliability measures (item-total correlation) and internal consistency (Cronbach's alpha). Correlations were performed between the Risk-Benefit and Self-Confidence indices, using Pearson's r. Analysis of variance (ANOVA) was also used to relate the indices of the scales with attitudes, actions and characteristics of the sample when there were more than two groups, and Student's t-test was used to compare means between two groups (according to independent variables).

\section{2.- Comparison with the original survey and with other studies that have used the same instrument}

After obtaining the statistical results, they were compared with the results of the other studies that have used the instrument of Twibell et al (2008). In this comparison, the same statistical procedures were used as in the original survey. Then, a comparison was made with the data resulting from the combination of the sociodemographic scales and the FPRB and FPSC from several studies that used the same instrument. 


\section{Results}

The sample is composed by 237 health professionals, who represent $43.8 \%$ of the hospital's professional population, and with a confidence level of $95 \%$, the sample margin of error was $4.78 \%$.

The survey was distributed among doctors and nurses. Regarding the total population of doctors and nurses, $47.4 \%$ of the doctors and $36.6 \%$ of the nurses of the hospital participated in the study. There is a higher presence of women (69\%) than men (31\%). In the sample, $48 \%$ of the health professionals are between 36 and 55 years of age, and $17 \%$ are older than 55 years. Fifty-one percent of the sample is composed of health professionals with more than 16 years of experience, with $24 \%$ of healthcare professionals having less than 5 years of experience and $51 \%$ of the sample having some specialty in their profession (Table 2). 


\begin{tabular}{|c|c|c|c|c|c|}
\hline QUESTIONS & Variables & $\begin{array}{l}\% \\
\text { CSG } \\
\text { Staff }\end{array}$ & QUESTIONS & Variables & $\begin{array}{l}\text { \% } \\
\text { CSG } \\
\text { Staff }\end{array}$ \\
\hline \multirow[t]{2}{*}{ 55.- Gender } & Man & $31 \%$ & \multirow{2}{*}{$\begin{array}{c}\text { 57R.- Do you hold a specialty in your } \\
\text { profession? }\end{array}$} & No & $49 \%$ \\
\hline & Woman & $69 \%$ & & Yes & $51 \%$ \\
\hline \multirow[t]{5}{*}{ 56.- Age (years) } & $20-25$ & $10 \%$ & \multirow{5}{*}{$\begin{array}{l}\text { 48.- Who should make the decision about } \\
\text { family presence during resuscitation efforts? }\end{array}$} & Physician & $67 \%$ \\
\hline & $26-35$ & $25 \%$ & & Pacient & $46 \%$ \\
\hline & $36-45$ & $24 \%$ & & Nurse & $42 \%$ \\
\hline & $46-55$ & $24 \%$ & & Family & $33 \%$ \\
\hline & Over 55 & $17 \%$ & & Others & $11 \%$ \\
\hline \multirow{3}{*}{$\begin{array}{l}\text { 54.- Highest level } \\
\text { of education } \\
\text { completed }\end{array}$} & $\begin{array}{l}\text { Graduated/Army } \\
\text { Professional }\end{array}$ & $48 \%$ & \multirow[t]{3}{*}{$\begin{array}{l}\text { 46.-How many times have you invited a family } \\
\text { member to be present during a resuscitation? }\end{array}$} & $>5$ times & $4 \%$ \\
\hline & Masters & $46 \%$ & & $<5$ times & $5 \%$ \\
\hline & Doctorate & $6 \%$ & & Never & $92 \%$ \\
\hline \multirow{6}{*}{$\begin{array}{l}\text { 53.- Years of } \\
\text { professional } \\
\text { experience }\end{array}$} & $\begin{array}{l}\text { Less than one } \\
\text { year }\end{array}$ & $5 \%$ & \multirow{2}{*}{$\begin{array}{l}\text { 44.-Would you want your family members to } \\
\text { be present if you are a patient who needs } \\
\text { resuscitation? }\end{array}$} & No & $73 \%$ \\
\hline & $1-5$ & $18 \%$ & & Yes & $27 \%$ \\
\hline & $6-10$ & $14 \%$ & \multirow{3}{*}{$\begin{array}{l}\text { 45.- Have you ever been present in the room } \\
\text { during the resuscitation of one of your family } \\
\text { members? }\end{array}$} & No & $87 \%$ \\
\hline & \begin{tabular}{|l|}
$11-15$ \\
\end{tabular} & $11 \%$ & & Yes & $13 \%$ \\
\hline & $16-20$ & $17 \%$ & & & \\
\hline & Over 20 years & $34 \%$ & \multirow{7}{*}{$\begin{array}{l}\text { 47.- In what unit were you working the last } \\
\text { time that you invited a family member to be } \\
\text { present during a resuscitation attempt? }\end{array}$} & Emergencies & $16 \%$ \\
\hline \multirow{9}{*}{$\begin{array}{l}\text { 51.- In which unit } \\
\text { do you work most } \\
\text { often? }\end{array}$} & $\begin{array}{l}\text { Acute Hosp. } \\
\text { Unit }\end{array}$ & $27 \%$ & & $\begin{array}{c}\text { Acute Hosp. } \\
\text { Unit }\end{array}$ & $14 \%$ \\
\hline & Emergencies & $25 \%$ & & $\begin{array}{c}\text { Social } \\
\text { healthcare }\end{array}$ & $9 \%$ \\
\hline & $\begin{array}{l}\begin{array}{l}\text { Social } \\
\text { healthcare }\end{array} \\
\end{array}$ & $22 \%$ & & ICU & $5 \%$ \\
\hline & ICU & $6 \%$ & & \begin{tabular}{|c|} 
External \\
Consultation \\
\end{tabular} & $1 \%$ \\
\hline & \begin{tabular}{|l|} 
External \\
Consultation
\end{tabular} & $5 \%$ & & Residency & $1 \%$ \\
\hline & Residency & $3 \%$ & & Others & $53 \%$ \\
\hline & \begin{tabular}{|l|}
$\begin{array}{l}\text { Hospital/Day } \\
\text { centre }\end{array}$ \\
\end{tabular} & $1 \%$ & \multirow[t]{3}{*}{ 52.- Profession } & Nurse & $69 \%$ \\
\hline & Rehabilitation & $0 \%$ & & Physician & $30 \%$ \\
\hline & Others & $11 \%$ & & Others & $1 \%$ \\
\hline
\end{tabular}

It is relevant that the sample is made up mostly of health professionals who work in hospital, emergency or social health care settings, so that it can be inferred that the information provided is based on their own experiences, since the interviewees work in areas where resuscitation is performed on a regular or occasional basis. In the survey, some questions take the FP issue to the personal sphere of the participants, and most of their responses were in the direction that they would not like their family members to be present during their resuscitation, especially for health professionals who work in the emergency room. Those who opted for their family members to be present are those who perceive more benefits in the FPDR. Healthcare providers who have experienced CPR barely reach $13 \%$, with the majority 
being men and older people. As far as the invitation to the FPDR is concerned, it barely reaches $5 \%$ and is recurrently $4 \%$. (Table 3 ).

Regarding the question of who should decide on the FPDR, $67 \%$ reported that it was the doctor, and $46 \%$ that the patient; $42 \%$ believe that it should be the nurse and $33 \%$ the family, but if they were made to choose the most appropriate person to make this decision, the majority (46\%) appointed the doctor, and only $26 \%$ believed that it should be the patient.

It is the doctors themselves who believe that they should make this decision, as well as the health professionals with more experience and age, and those who believe that there are more risks related to the presence of family members, and also those who feel less confident in the presence of family members during resuscitation. (Table 3 )

Health care professionals who work in the social health field, the youngest and least experienced respondents, and those who have higher self-confidence in the presence of family members believe that it is the patient who should decide.

Regarding the willingness to include FP in advance directives, $66 \%$ of healthcare professionals are in favor.

Emergency medical and nursing staff see more risks and fewer benefits to FPDR and rely less on themselves to face this possibility. On the other hand, hospital and social health workers see more benefits than risks, with those in the social health field being more self-confident. 


\begin{tabular}{|c|c|c|c|c|c|c|c|c|}
\hline QUESTIONS & 44 & 45 & 46 & $49 a$ & $49 b$ & 50 & & QUESTIONS \\
\hline AGE (\%) & $27,4 \%$ & $12,7 \%$ & $8,4 \%$ & $45,6 \%$ & $26,2 \%$ & $65,8 \%$ & \multirow[t]{7}{*}{44} & \multirow{7}{*}{$\begin{array}{l}\text { If I were a patient under } \\
\text { resuscitation, I would like } \\
\text { my family to be present in } \\
\text { the room. }\end{array}$} \\
\hline $20-35(n=83)$ & $25 \%$ & $6 \%$ & $7 \%$ & $31 \%$ & $39 \%$ & $72 \%$ & & \\
\hline $36-55(n=113)$ & $28 \%$ & $15 \%$ & $9 \%$ & $47 \%$ & $24 \%$ & $66 \%$ & & \\
\hline$>55(\mathrm{n}=41)$ & $29 \%$ & $20 \%$ & $10 \%$ & $71 \%$ & $7 \%$ & $51 \%$ & & \\
\hline Value Chisq & 0,3 & 5,63 & 0,27 & 17,34 & 14,44 & 5,44 & & \\
\hline P-value chisq & 0,86 & 0,06 & 0,87 & 0,00 & 0,00 & 0,07 & & \\
\hline Cohen's d & $\overline{----}$ & --- & --- & 0,56 & 0,51 & --- & & \\
\hline \multicolumn{7}{|l|}{ GENDER } & \multirow[t]{5}{*}{45} & \multirow{5}{*}{$\begin{array}{l}\text { I have been present in the } \\
\text { room during the } \\
\text { resuscitation of one of my } \\
\text { relatives. }\end{array}$} \\
\hline MEN $(n=73)$ & $30 \%$ & $22 \%$ & $11 \%$ & $49 \%$ & $29 \%$ & $60 \%$ & & \\
\hline $\begin{array}{l}\text { WOMEN } \\
(\mathrm{n}=164)\end{array}$ & $26 \%$ & $9 \%$ & $7 \%$ & $44 \%$ & $25 \%$ & $68 \%$ & & \\
\hline Value Chisq & 0,39 & 8,18 & 0,87 & 0,6 & 0,37 & 1,44 & & \\
\hline P-value chisq & 0,53 & 0,00 & 0,35 & 0,44 & 0,54 & 0,23 & & \\
\hline Cohen's d & --- & 0,38 & $\begin{array}{l}---- \\
\end{array}$ & $\begin{array}{l}---- \\
\end{array}$ & ----- & $\begin{array}{ll}--- \\
\end{array}$ & \multirow[t]{6}{*}{46} & \multirow{6}{*}{$\begin{array}{c}\text { I have sometimes invited a } \\
\text { family member to be present } \\
\text { during resuscitation. }\end{array}$} \\
\hline \multicolumn{7}{|c|}{ PROFESSIONAL STATUS } & & \\
\hline Nurse $(n=163)$ & $31 \%$ & $12 \%$ & $9 \%$ & $38 \%$ & $31 \%$ & $72 \%$ & & \\
\hline Doctor $(\mathrm{n}=72)$ & $21 \%$ & $14 \%$ & $7 \%$ & $63 \%$ & $14 \%$ & $51 \%$ & & \\
\hline Value Chisq & 2,42 & 0,12 & 0,33 & 12,05 & 8,34 & 9,81 & & \\
\hline P-value chisq & 0,12 & 0,73 & 0,57 & 0,00 & 0,00 & 0,00 & & \\
\hline Cohen's d & ---- & ---- & ---- & 0,46 & 0,38 & 0,41 & \multirow[t]{4}{*}{$49 a$} & \multirow{4}{*}{$\begin{array}{l}\text { Believe the doctor is the } \\
\text { most adequate person to } \\
\text { decide about FPDR }\end{array}$} \\
\hline \multicolumn{7}{|l|}{ HOSPITAL UNIT } & & \\
\hline $\begin{array}{l}\text { Acute Hosp } \\
\text { Unit }(\mathrm{n}=63) \\
\end{array}$ & $35 \%$ & $16 \%$ & $11 \%$ & $48 \%$ & $24 \%$ & $75 \%$ & & \\
\hline $\begin{array}{l}\text { Emergency } \\
(\mathrm{n}=59)\end{array}$ & $14 \%$ & $14 \%$ & $3 \%$ & $46 \%$ & $27 \%$ & $56 \%$ & & \\
\hline $\begin{array}{l}\text { Social } \\
\text { Healthcare } \\
(\mathrm{n}=51)\end{array}$ & $39 \%$ & $4 \%$ & $8 \%$ & $27 \%$ & $37 \%$ & $80 \%$ & \multirow[t]{5}{*}{$49 \mathrm{~b}$} & \multirow{5}{*}{$\begin{array}{l}\text { Believe THE PATIENT is the } \\
\text { most adequate person to } \\
\text { decide about family } \\
\text { presence during } \\
\text { resuscitation }\end{array}$} \\
\hline Value Chisq & 15,45 & 6,74 & 5,68 & 9,06 & 5,15 & 17,34 & & \\
\hline P-value chisq & 0,00 & 0,08 & 0,13 & 0,03 & 0,16 & 0,00 & & \\
\hline Cohen's d & 0,53 & --- & $\begin{array}{l}--- \\
-1\end{array}$ & 0,4 & $-\overline{---}$ & 0,56 & & \\
\hline \multicolumn{7}{|c|}{ YEARS OF EXPERIENCE } & & \\
\hline$<5(\mathrm{n}=56)$ & $25 \%$ & $5 \%$ & $0 \%$ & $30 \%$ & $43 \%$ & $64 \%$ & \multirow[t]{2}{*}{50} & \multirow[t]{2}{*}{$\begin{array}{l}\text { The decision about family } \\
\text { presence must be part of a }\end{array}$} \\
\hline $6-20(n=100)$ & $33 \%$ & $13 \%$ & $9 \%$ & $45 \%$ & $31 \%$ & $78 \%$ & & \\
\hline
\end{tabular}




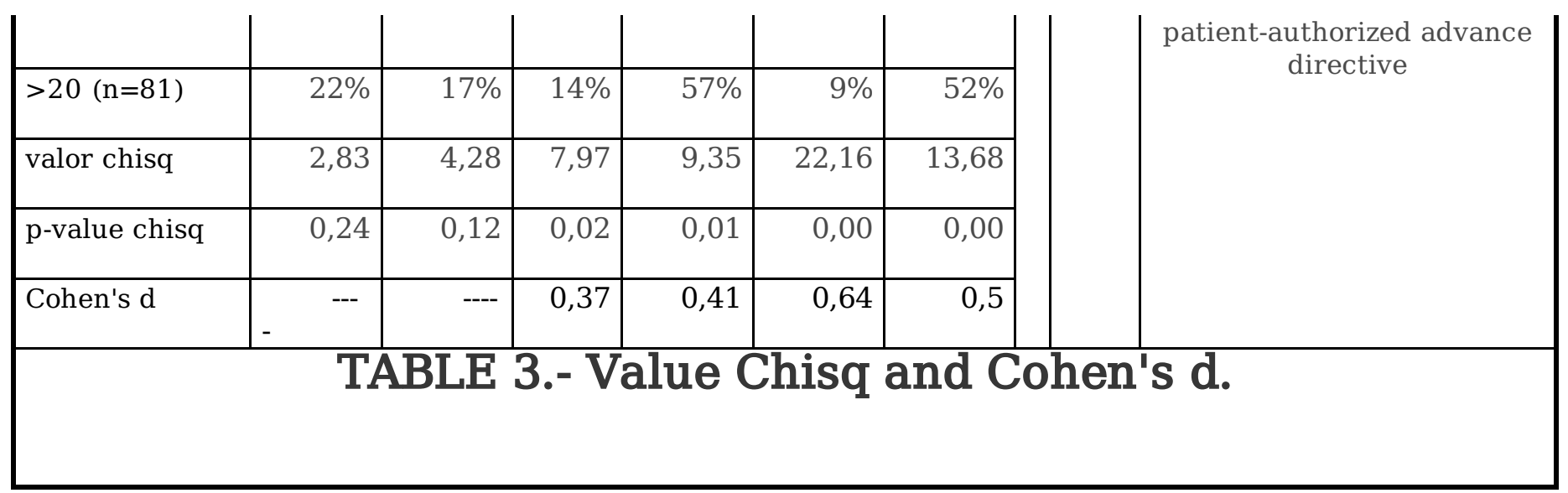

A total of $76 \%$ of participants in the survey responded the open question about the main reasons for not offering the FPDR, and there were three reasons: emotional impact (42\%), fear of the families' disruptive reaction (25\%) and distrust of the resuscitation team not feeling comfortable and unable to work under pressure (22\%), all of them conditioning the results of the procedures. The three main reasons in favor of offering FPDR are: the request of the family members themselves (21\%) (by the patient or family), the fact that families can verify that everything possible has been done for their loved one (20\%) and can better understand the resuscitation procedure, and the accompaniment between the family and the patient during CPR (17\%).

In the survey questions from 44 to 50 (see Table 3), participants are directly asked about their personal opinion and experiences of Family Presence. Most of responses in this set of questions were in the direction that they would not like their family members to be present if they were resuscitated. Specifically, the most reluctant healthcare professionals are those who work in the emergency care.

The prevailing view is that it is the physician who should make the decision on the FPDR and that the patients should include it in their advance directives.

The correlation between the two scales (RB/SC) is significant and with a moderate intensity of the relationship $(r=0.65$ and $a<0.001)$.

To measure the effect size, Cohen's d was incorporated, following the instructions of J. Cohen (27).

\section{VALIDITY OF THE INSTRUMENT.}

To validate the instrument, its reliability indices were calculated: Cronbach's alpha and item-total correlations. In the Risk-Benefit index, there were five items $(5,8,12,13$ and 14$)$ identified as poorly correlating with the total $(r<0.3)$, so they were removed. After the removal of these items, the calculations of the Risk-Benefit index yielded a Cronbach's alpha of 0.95 (Table 4).

In the Self-Confidence index, the correlation of all items with the total was greater than 0.5 , so no changes were necessary. Cronbach's alpha in this construct equals 0.94 (Table 4). 
Applying factor analysis, the KMO measure is greater than 0.9 , which indicates the suitability of the variables. The Risk-Benefit and Self-confidence indices maintain a moderate correlation of $r=0.65$ in a positive sense.

In the analytical sense of the Index of Risks and Benefits of the presence of relatives in our replica, three realities are measured:

- Factor 1: the role of patients and relatives in resuscitation (rights, attitudes, effects of FP on them...)

- Factor 2: benefits of FP for doctors and nurses.

- Factor 3: effects of FP on satisfaction surveys

In the Self-confidence Index: we find TWO realities, two different expressions of the concept of selfconfidence:

- Factor 1: self-confidence towards the relationship with the family during resuscitation

- Factor 2: self-confidence towards the technical aspects of professional practice during resuscitation (administration of medication, electrical therapy, chest compression...) 


\begin{tabular}{|c|c|c|c|c|c|c|c|c|c|}
\hline \multicolumn{2}{|c|}{$\begin{array}{c}\text { Perceptions of Self- } \\
\text { Confidence in FPDR. } \\
\text { Item number } \\
\text { (original order) }\end{array}$} & $\begin{array}{l}\text { Loads } \\
\text { F1 } \\
34 \%\end{array}$ & $\begin{array}{l}\text { Loads } \\
\text { F2 } \\
20 \%\end{array}$ & $\begin{array}{l}\text { Loads } \\
\text { F3 } \\
11 \%\end{array}$ & \multicolumn{2}{|r|}{$\begin{array}{c}\text { Risk-Benefit } \\
\text { Perception in } \\
\text { FPDR } \\
\text { Item number } \\
\text { (original order) }\end{array}$} & $\begin{array}{l}\text { Loads } \\
\text { F1 } \\
24 \%\end{array}$ & $\begin{array}{l}\text { Loads } \\
\text { F2 } \\
21 \%\end{array}$ & $\begin{array}{l}\text { Loads } \\
\text { F3 } \\
14 \%\end{array}$ \\
\hline 1 & $\begin{array}{l}\text { I could inform the } \\
\text { relatives present } \\
\text { during the } \\
\text { resuscitation } \\
\text { procedure. }\end{array}$ & 0.666 & & & 1 & $\begin{array}{c}\text { Family members } \\
\text { should be given } \\
\text { the option of being } \\
\text { present while their } \\
\text { loved one is } \\
\text { undergoing an } \\
\text { invasive } \\
\text { procedure. }\end{array}$ & 0.761 & & \\
\hline 2 & $\begin{array}{l}\text { I could administer } \\
\text { medication during a } \\
\text { resuscitation } \\
\text { witnessed by } \\
\text { relatives }\end{array}$ & & 0.882 & & 2 & $\begin{array}{c}\text { Family members } \\
\text { would be terrified } \\
\text { to witness the } \\
\text { technique of an } \\
\text { invasive } \\
\text { procedure. }\end{array}$ & -0.477 & & \\
\hline 3 & $\begin{array}{l}\text { I could administer } \\
\text { electrical therapies } \\
\text { (defibrillation, } \\
\text { cardioversion, etc.) } \\
\text { during family- } \\
\text { witnessed } \\
\text { resuscitation. }\end{array}$ & & 0.904 & & 3 & $\begin{array}{l}\text { Family members } \\
\text { will have long- } \\
\text { term difficulties in } \\
\text { coping with the } \\
\text { emotional impact } \\
\text { of having } \\
\text { witnessed a } \\
\text { resuscitation. }\end{array}$ & -0.54 & & \\
\hline 4 & $\begin{array}{l}\text { I could perform } \\
\text { thoracic } \\
\text { compressions during } \\
\text { resuscitation with } \\
\text { relatives present. }\end{array}$ & & 0.866 & & 4 & $\begin{array}{l}\text { The resuscitation } \\
\text { team could } \\
\text { develop a close } \\
\text { relationship with } \\
\text { family members } \\
\text { who witness } \\
\text { resuscitation } \\
\text { efforts compared } \\
\text { to family members } \\
\text { who do not } \\
\text { witness them. } \\
\end{array}$ & 0.551 & & \\
\hline 5 & $\begin{array}{l}\text { I could communicate } \\
\text { effectively with the } \\
\text { rest of the healthcare } \\
\text { team during } \\
\text { resuscitation } \\
\text { witnessed by family } \\
\text { members. }\end{array}$ & 0.52 & 0.57 & & 6 & $\begin{array}{l}\text { I would like to be } \\
\text { present if a loved } \\
\text { one were revived. }\end{array}$ & 0.54 & & \\
\hline 6 & $\begin{array}{l}\text { I could maintain the } \\
\text { dignity of the patient } \\
\text { during a family- } \\
\text { witnessed } \\
\text { resuscitation. }\end{array}$ & 0.591 & & & 7 & $\begin{array}{l}\text { Patients DO NOT } \\
\text { want their } \\
\text { relatives to be } \\
\text { present during } \\
\text { resuscitation } \\
\text { attempts. } \\
\end{array}$ & -0.522 & & \\
\hline 7 & $\begin{array}{l}\text { I could identify the } \\
\text { relatives that have } \\
\text { adequate behaviors } \\
\text { during resuscitation. }\end{array}$ & 0.611 & & & 9 & $\begin{array}{l}\text { Family members } \\
\text { who witness a } \\
\text { failed } \\
\text { resuscitation will } \\
\text { have a better and } \\
\text { healthier grieving } \\
\text { process. }\end{array}$ & 0.546 & & \\
\hline 8 & $\begin{array}{l}\text { I could prepare the } \\
\text { family to access the } \\
\text { area of resuscitation } \\
\text { of their loved one. }\end{array}$ & 0.76 & & & 10 & $\begin{array}{l}\text { If my loved one is } \\
\text { being } \\
\text { resuscitated, they } \\
\text { should allow me to }\end{array}$ & 0.365 & & \\
\hline
\end{tabular}




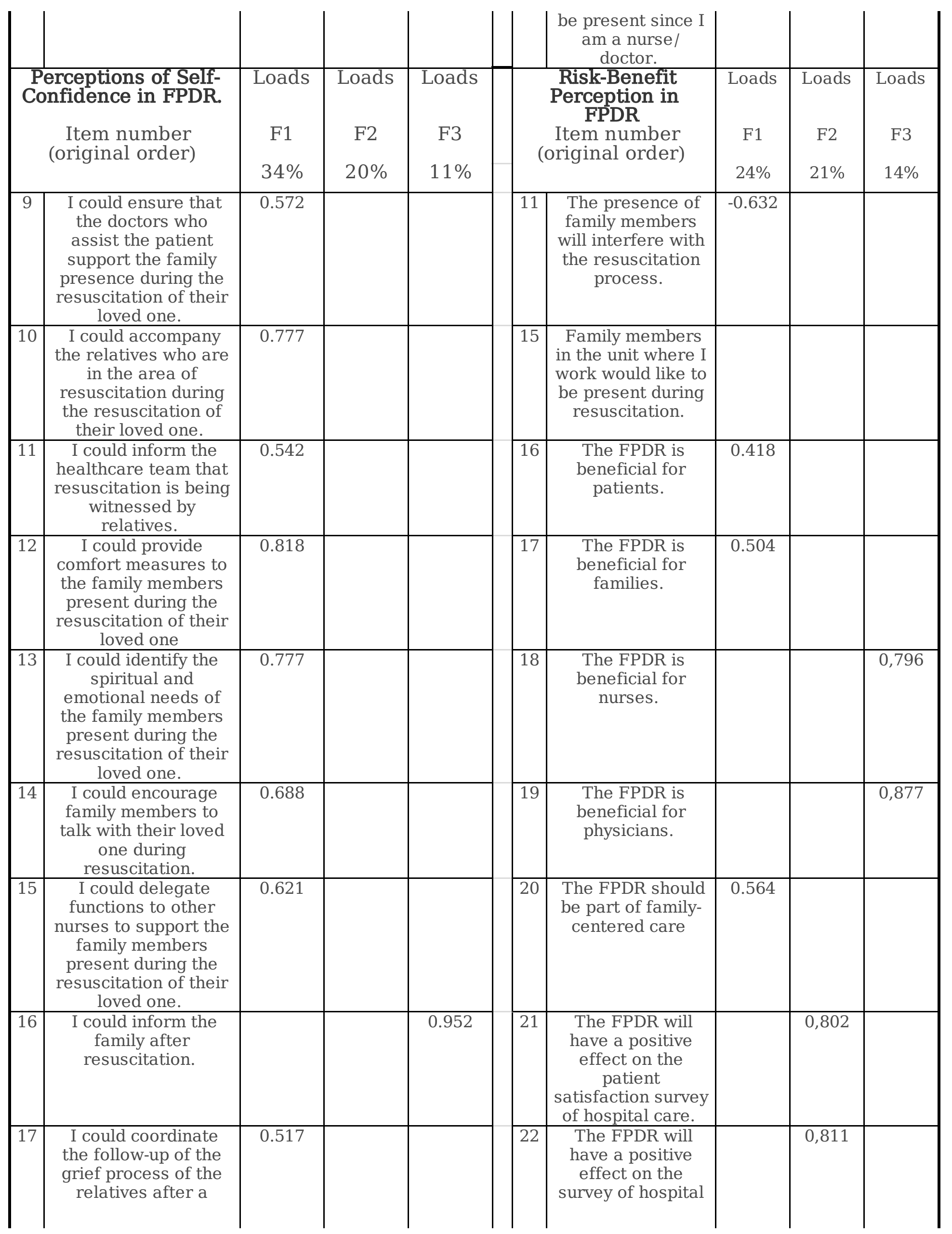




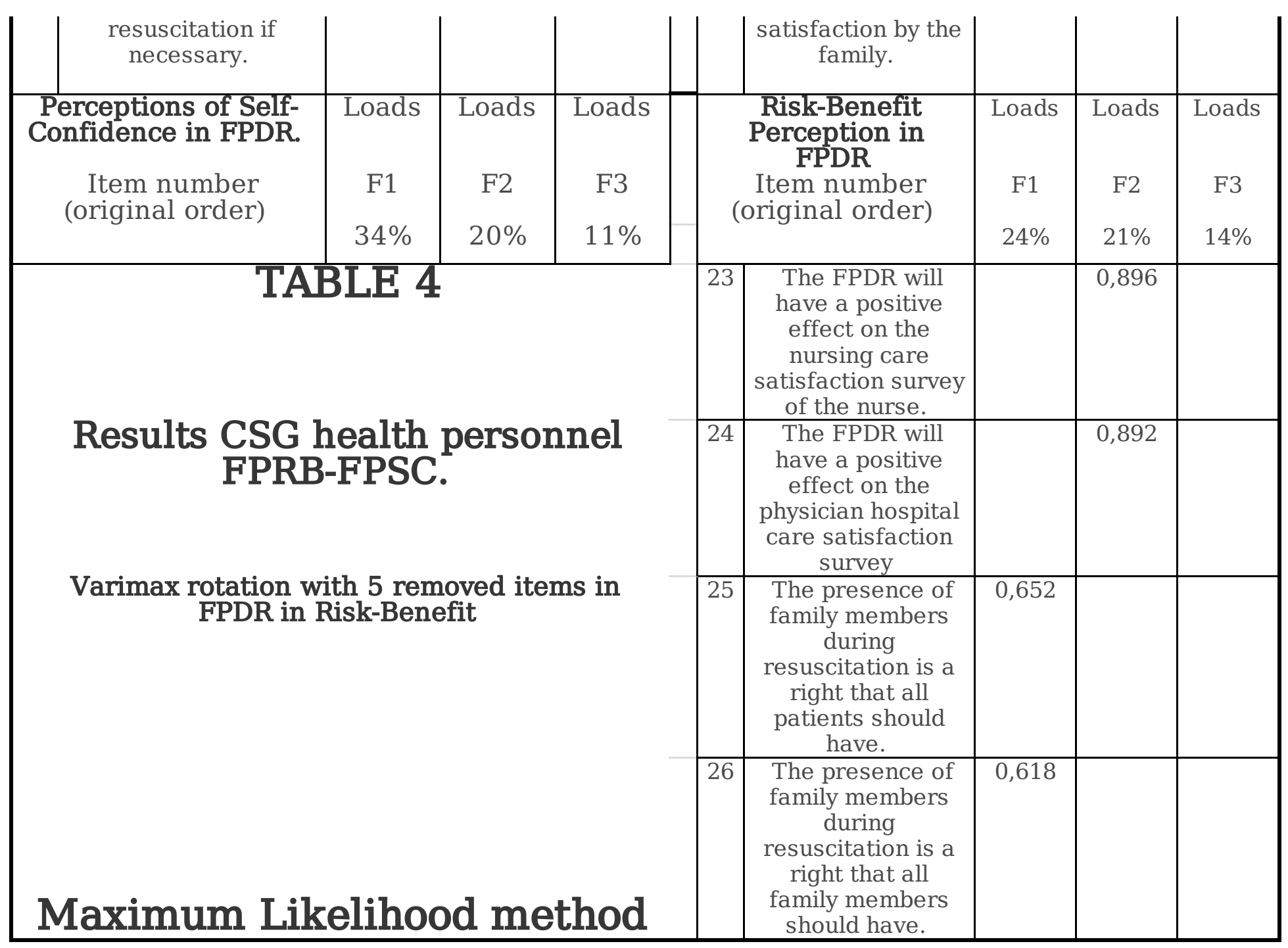

\section{Discussion}

Compared with the study by Twibell et al. (2008) and in reference to the validity of the indices, a more dispersed distribution has been obtained, with higher indices of asymmetry and kurtosis, to the point that the self-confidence index does not comply with the principle of normality. In both questionnaires, the Cronbach's $a$ is very similar, with our FPRB being $a=0.95$ in RB and $a=0.96$ that of Twibell et al (2008); FPSC obtained an $a=0,94$ while Twibell et al. (2008) obtained $a=0.95$, so we can affirm that we were able to replicate the reliability of both indices. As for the correlation between the two scales (FPRB-FPSC), it is significant and has a moderate intensity of the relationship $(r=0.65$ and $a<0.001)$, while the one by Twibell et al (2008), gave an $r=0.56$ and an $a<0.001$, slightly below the results from this study.

In the factorial analysis, six variables have been found not to work well in the Risk-Benefit index, three of them have been removed from both studies and the remaining ones have either been excluded or obtained low factorial loads in one or the other study. (Table 4)

The fundamental difference with Twibell et al (2008) is that in our study, there are additional variables that have generated different correlations in certain factors. Thus, it is worth asking what underlying 
dimensions they were meant to measure: risks, benefits or self-confidence, since different meanings of these concepts emerge from the results, either due to polysemy or because they are items that do not define these dimensions well. For example, polysemy was found in the self-confidence index, since health care providers' self-confidence behaves differently if one speaks from the social perspective (treatment of families, communication), in that those who agree on FP are more confident and those who disagree are less confident, or if one speaks of technical procedures that are assumed to be performed whether they agree or disagree with FP.

The perceptions of the effect of FP on satisfaction surveys measure a risk or a benefit, since in all combinations of factor analysis, these are variables that do not correlate with the rest of the index items.

It does not seem that transcultural translation has produced any disturbance, but rather that the healthcare professionals participating in this study have different opinions than health professionals in the United States sample.

For the comparison of the sample, the inclusion of doctors in the study has made it possible to increase the presence of men and older professionals with more extensive experience, although the differences between medical and nursing staff have not been significant in most of the variables, as in the McLean $^{(24)}$ and Chapman ${ }^{(25)}$ studies, which did include physicians in the sample. The sample in this study, although smaller $(n=237)$, is more representative in terms of hospital units. (Table 5).

\begin{tabular}{|c|c|c|c|c|c|}
\hline \multicolumn{2}{|c|}{ RESULTS TWIBELL et al (2008) } & \multirow{2}{*}{\begin{tabular}{l|}
$\%$ \\
95.7
\end{tabular}} & \multicolumn{2}{|c|}{ RESULTS CSG HEALTH PROFESSIONALS } & \multirow{2}{*}{$\begin{array}{l}\% \\
69.2\end{array}$} \\
\hline GENDER & Woman & & \multirow[t]{2}{*}{ GENDER } & Woman & \\
\hline & Man & 2.1 & & Man & 31.8 \\
\hline \multirow[t]{4}{*}{ AGE (years) } & Less than 24 years & 4.5 & \multirow[t]{3}{*}{ AGE (years) } & From 20 to 35 & 35.0 \\
\hline & From 25 to 39 & 38.1 & & From 36 to 55 & 47.7 \\
\hline & From 40 to 55 & 46.1 & & More than 55 & 17.3 \\
\hline & More than 55 & 8.5 & \multirow[t]{5}{*}{$\begin{array}{l}\text { Years of } \\
\text { experience }\end{array}$} & Less than 1 & 5.5 \\
\hline \multirow{5}{*}{$\begin{array}{l}\text { Years } \\
\text { of } \\
\text { experience }\end{array}$} & Less than 1 & 3.7 & & From 1 to 5 & 18.1 \\
\hline & From 1 to 5 & 18.4 & & From 6 to 10 & 14.3 \\
\hline & From 6 to 10 & 21.9 & & From 11 to 20 & 27.8 \\
\hline & From 11 to 20 & 30.7 & & More than 20 years & 34.2 \\
\hline & More than 20 years & 23.5 & \multirow{3}{*}{$\begin{array}{l}\text { Highest level of } \\
\text { education } \\
\text { completed }\end{array}$} & Graduate & \multirow[t]{2}{*}{$\overline{48.1}$} \\
\hline \multirow[t]{4}{*}{$\begin{array}{l}\text { Highest level of } \\
\text { education completed }\end{array}$} & \multirow{2}{*}{$\begin{array}{l}\text { Graduate } \\
\text { MA } \\
\text { Assimilated/Qualified }\end{array}$} & \multirow[t]{2}{*}{78} & & $\begin{array}{l}\text { MA } \\
\text { Assimilated/Qualified }\end{array}$ & \\
\hline & & & & Postgraduate/Doctorate & 51.9 \\
\hline & Postgraduate/Doctorate & 3.7 & & & \\
\hline & Auxiliary nurse & & \multicolumn{3}{|c|}{$\begin{array}{l}\text { Table 5. Comparative sociodemographic } \\
\text { data. }\end{array}$} \\
\hline
\end{tabular}


We observe that in comparison with the sample of Twibell et al (2008), in this study we have obtained a much smaller presence of professionals who have sometimes invited a family member to witness resuscitation, which makes it impossible to evaluate this item, since there were barely 20 cases.

A lower predisposition to FPDR is observed, due to a higher risk perception and lower self-confidence than in Twibell et al (2008), and this is the main result obtained from this study. This can be explained taking into account the different characteristics of the sample, especially the participation of doctors, who are the ones that value PF the worst, but we believe that the key is in the cultural differences, since in this study there are a lot fewer professionals that have ever invited the relatives to attend a resuscitation process and this constitutes a conditioning pattern that can influence all the rest. A difference has been observed between the assessments of the emergency staff, which would be a very interesting subject for further investigation.

An index correlation very similar to that of Twibell et al (2008) has been obtained: the medical and nursing professionals who perceive more benefits are the ones who are more confident of being able to manage the presence of the families.

Another key difference is that in this study no single explanatory factor has been obtained to explain the perception about inviting or not inviting relatives to resuscitation, and that the qualitative questions have allowed to confirm that the main barriers to invite relatives coincide with the theoretical framework presented by Twibell et al (2008): avoidance of causing an unpleasant impact on families, fear of a disruptive reaction from families, and fear of the resuscitation team not working comfortably. However, the main reasons for inviting family members presented by Twibell et al (2008) in their study are not the ones most frequently mentioned by the participants of our study. The fact that families understand that everything was done for their loved one is one of the reasons mentioned by one in five participants, positive grief management is mentioned by one in ten, not emphasizing the understanding of the severity of the patient.

Overall, the FPDR rating is more positive than negative. In relative terms to the index averages, we have $48 \%$ of "detractors" but in absolute terms only $12 \%$ of the participants are pure detractors, because the scores of both indexes are below 2.5 .

Doctors are more reluctant to FPDR than nurses, especially in emergency care and intensive care units. This aspect contrasts with the McLean(24) and Chapman(25) studies, where there are no significant differences in the perceptions of self-confidence, but it must be pointed out that in the center where the McLean study was carried out, training programs and protocols on PFDR were implemented, thus conditioning this perception. Also professionals with specialties were found to be more reluctant, but this variable is very much influenced by the profession, since it is doctors who have specialties and most nurses do not have them, in part due to the recent incorporation of specialties in Spain. It is interesting to note that it is in the area of emergency care where they are most reluctant to FPDR, since it is the area where they have contact with this procedure most often, and also that it is in the social health field, where 
these procedures are hardly performed, where they have the most self-confidence, a result that could open doors to future investigations.

When asked who should make the decision, those who choose to give more responsibility to medical staff are those who see more risk in FP and who have less confidence in themselves (especially older, more experienced physicians). In contrast, those who see greater benefits and have more self-confidence (nurses and young professionals with less than five years of experience), choose to give the decision responsibility to the patient.

It is observed that, behind the attitudes, there is a background of generational change that is advancing to allow FP. In this regard, the same trend is observed when we ask whether FP should be part of the patient's advance directives.

In our study, many professionals (26\%) report a lack of specific training and protocols to successfully perform FPDR, a factor that coincides with the studies by Chapman(25) and Powers(21), stating that "a key predictor to support FPDR is to receive training and have specific protocols".

It would be interesting to reproduce this tool in other Spanish-speaking contexts, in order to analyze its reliability outside the context studied.

\section{Limitations}

The results of this study should be interpreted with caution due to their limitations. One limitation was related to the method of data collection (manual and electronic). Almost $50 \%$ of the population participated in the study. The relatively small sample can possibly be explained by the fact that this topic is still quite unknown and may cause uncomfortable emotions, which could negatively impact the willingness to participate in the study.

While in Twibell et al (2008), the original study obtained data that did not include a "do not know/no answer" option for each question, this study provided data that did take this answer option into account. There are advantages to this decision, since it does not force the participants to choose an answer when faced with doubts, but on the other hand, it can sometimes be used as an evasive category when faced with a decision in a specific situation.

Medical and nursing staff, who have at some point witnessed a loved one's CPR, are mostly men and there may be a gender bias in FPDR.

A greater perception of risk and lower self-confidence is observed, especially among emergency care providers, than in the sample by Twibell et al (2008). Health professionals with greater self-confidence consider FP to be more beneficial.

The difference of 12 years between the original study and this study must be taken into account, since society's opinion and the training of health professionals change with regard to the principles of 
bioethics, especially that of autonomy, which gives more empowerment to the patient and the family, leaving behind clinical decisions of medical paternalism.

\section{Conclusions}

The proposed indices are valid with the variables with which they are constructed since they offer high reliability indices. However, there are some variables that have been removed due to low correlation, as in the study by Twibell et al (2008). Some of the variables have generated additional unexpected factors. Of the 26 variables of the risk index, 14 variables that measure the same thing have been secured. Out of the 17 variables in the self-confidence index, 13 are part of the same factor. It is worth reflecting on whether it is preferable to discard some of the variables that now form part of the indexes or whether the fact that the index has different dimensions constitutes a value to be preserved.

FP generates controversy among health professionals, with doctors and nurses differing in their opinions, the latter being more in favor of FP. There is a trend towards generational change, as younger and less experienced health professionals tend to have greater acceptance of FP.

A possible explanation for the different attitudes toward FPDR among health professionals in different countries could be related to cultural differences and different healthcare models.

More studies on FPDR are needed in Spanish-speaking regions, and therefore it would be advisable to replicate this study to ensure the reliability and validity of the instrument in different health and sociocultural contexts.

\section{List Of Abbreviations}

- Cardiopulmonary Resuscitation.

- Consorci Sanitari de l'Alt Penedés i Garraf.

- Consorci Sanitari del Garraf.

- Family Presence.

- Family Presence during Resuscitation.

- Family Presence Risk Benefit scale.

- Family Presence Self Confidence scale.

- Family Witnessed Resuscitation.

- World Health Organization. 


\section{Declarations}

\section{Ethics approval and consent to participate}

The study was approved by the institutional review board of the Consorci Sanitari del Garraf, and by the clinical research Ethic Committee of the Fundació Unió Catalana Hospitals with code CEIC 15/31.

The author of the survey, Twibell R, provided written permission to use, translate and modify the tool as needed.

The consent of the participation in the study is implicit to answer the survey anonymously.

\section{Consent for Publication}

Not applicable

\section{Availability of data and materials.}

The data sets used and/or analyzed during the current study are available from the corresponding author upon reasonable request.

\section{Competing Interests}

The authors declare that they have no competing interests.

\section{Funding}

There has been no funding from any organization to carry out this work.

\section{Authors' Contributions}

All the authors have read and approved the manuscript.

EdM-F- Predoctoral Student and main author of the article.

$\underline{A}$ B-E.-He has collaborated in the review of the methodological part, more specifically, in the Review of the Analysis.

$\underline{\mathrm{M} \mathrm{J}-\mathrm{H}}$. She has collaborated in the review of the whole paper. She is the tutor of Eva de Mingo's doctoral thesis

\section{Acknowledgements}

We thank Renee Twibell for her collaboration, both for letting us translate the FPSC-FPRB scales into Spanish, and for her constructive feedback on our study. 
I also want to thank the CSAPG for allowing me to use their facilities and their research department to carry out the study, with special thanks to Dr. Antonio Yuste, Esther Valldosera, Dr. Cesar Gálvez and Dr. Alejandro Rodríguez-Molinero, for advising me and facilitating the access to the resources for my research.

\section{Authors' information.}

EdM-F Nurse in the Consorci Sanitari de l'Alt Penedès I Garraf (CSAPG) (Barcelona) and collaborator in the research department. Associate professor in the nursing department of the URV for 4 years and currently, predoctoral fellow at the Fundación Martí Franqués

ÁB-E. Tenured professor of Science Methodology and Data Analysis in the Rovira i Virgili University (URV). PhD in Sociology at the Universitat Autònoma de Barcelona and Postgraduate in Demography at the same university. Director of the Social Inclusion Chair of the URV. As research coordinator, he has developed leading competences on team management both in managing a research group of URV (SBRlab, with 20 members) and coordinating projects. He coordinated a national project on poverty and gender that involved 6 different universities. He was the scientific co-director of the European project ICUD, in which he developed a methodology of procedures implemented by international partners.

MJ-H. Tenured professor of Ethics at the Nursing Faculty of the Rovira i Virgili University. PhD in Social and Cultural Anthropology. Master in Bioethics and Diploma in Criminology

\section{References}

1. Porter JE, Cooper SJ, Sellick K. Family presence during resuscitation (FPDR): Perceived benefits, barriers and enablers to implementation and practice. Int Emerg Nurs [Internet]. 2014;22(2):69-74. Available from: http://linkinghub.elsevier.com/retrieve/pii/S1755599X13000657

2. Tudor BK, Berger J, Polivka BJ, Chlebowy R, Thomas B. Nurses'Perceptions of Family Presence During Resuscitation. 2014;23(6).

3. Chapman R, Bushby A, Watkins R, Combs S. Australian Emergency Department health professionals' reasons to invite or not invite Family Witnessed Resuscitation: A qualitative perspective. Int Emerg Nurs [Internet]. 2014;22(1):18-24. Available from: http://dx.doi.org/10.1016/j.ienj.2013.03.008

4. Johnson C. A literature review examining the barriers to the implementation of family witnessed resuscitation in the Emergency Department. Int Emerg Nurs [Internet]. 2017;30:31-5. Available from: http://dx.doi.org/10.1016/j.ienj.2016.11.001

5. Giles T, de Lacey S, Muir-Cochrane E. How do clinicians practise the principles of beneficence when deciding to allow or deny family presence during resuscitation? J Clin Nurs. 2018;27(5-6):e121424.

6. Waldemar A, Thylen I. Healthcare professionals' experiences and attitudes towards family-witnessed resuscitation: A cross-sectional study. Int Emerg Nurs [Internet]. 2019;42(May 2018):36-43. Available from: https://doi.org/10.1016/j.ienj.2018.05.009 
7. Dall 'orso S, Jara Concha P. PRESENCIA fAMILIAR DURANTE LA REANIMACIÓN CARDIOPULMONAR: LA MIRADA DE ENfERMEROS Y fAMILIARES FAMILy PRESENCE DURING CARDIOPULMONARy RESUSCITATION: ThE LOOK OF NURSES AND FAMILy. Cienc y enfermería XVIII. 2012;(3):83-99.

8. Axelsson AB, Zettergren M, Axelsson C. Good and bad experiences of family presence during acute care and resuscitation. What makes the difference? Eur J Cardiovasc Nurs [Internet]. 2005;4(2):1619. Available from: http://www.ncbi.nlm.nih.gov/pubmed/15904887

9. Mazer M. Witnessed Cardiopulmonary resuscitation: The public's perception. In: Care C, editor. 2004. p. P296.

10. Sheng CK, Lim CK, Rashidi A. A multi-center study on the attitudes of Malaysian emergency health care staff towards allowing family presence during resuscitation of adult patients. Int J Emerg Med. 2010;3(4):287-91.

11. Kianmehr N, Mofidi M, Rahmani H, Shahin Y. The attitudes of team members towards family presence during hospital-based CPR: A study based in the Muslim setting of four Iranian teaching hospitals. J R Coll Physicians Edinb. 2010;40(1):4-8.

12. Dwyer TA. Predictors of public support for family presence during cardiopulmonary resuscitation: $A$ population based study. Int J Nurs Stud [Internet]. 2015;52(6):1064-70. Available from: http://dx.doi.org/10.1016/j.ijnurstu.2015.03.004

13. Toronto CE, LaRocco SA. Family perception of and experience with family presence during cardiopulmonary resuscitation: An integrative review. J Clin Nurs. 2019;28(1-2):32-46.

14. Leung NY, Chow SKY. Attitudes of healthcare staff and patients' family members towards family presence during resuscitation in adult critical care units. J Clin Nurs. 2012;21(13-14):2083-93.

15. Tíscar-González V, Gastaldo D, Moreno-Casbas MT, Peter E, Rodriguez-Molinuevo A, Gea-Sánchez M. Presencia de familiares durante la reanimación cardiopulmonar: perspectivas de pacientes, familiares y profesionales de la salud en el País Vasco. Aten Primaria [Internet]. 2019;51(5):269-77. Available from: https://doi.org/10.1016/j.aprim.2017.12.002

16. Paplanus LM, Salmond SW, Jadotte YT. A Systematic Review of Family Witnessed Resuscitation and Family Witnessed Invasive Procedures in Adults in Hospital Settings Internationally - Part II: Perspectives of Healthcare Providers. 2018;10(33):2018-294.

17. Fullbrook, Paul. Latour, Jos. Albarran, John. de Graaf, Wouter. Lynch, Fiona. Devictor, Denis. Norekval T. The Presence of FAmily Members During Cardiopulmonary Resuscitation:the European federation of Critical Care Nursing associations, the European Society of Paediatric and Neonatal Intensive Care, the Council on Cardiovascular Nursing and Allied Professions. Connect World Crit Care Nurs. 2007;5(4):86-8.

18. Moons $P$, Norekvål TM. European nursing organizations stand up for family presence during cardiopulmonary resuscitation: A joint position statement. Prog Cardiovasc Nurs. 2008;23(3):136-9.

19. Tenee Twibell, Debra Siela, Cheryl Riwitis, Tina Riegle, Denise Bousman, Sandra Cable, Pam Caudill, Sherry Harrigan, Rick Hollars, Doreen Johnson AN. Nurses'Perceptions of their Self-Confidence and the Benefits and Risks of Family Presence During Resuscitation. Am J Crit Care. 2008;17(2):646-53. 
20. Sousa VD, Rojjanasrirat W. Translation, adaptation and validation of instruments or scales for use in cross-cultural health care research: A clear and user-friendly guideline. J Eval Clin Pract. 2011;17(2):268-74.

21. Powers K, Reeve CL. Factors associated with nurses' perceptions, self-confidence, and invitations of family presence during resuscitation in the intensive care unit: A cross-sectional survey. Int J Nurs Stud [Internet]. 2018;87(December 2017):103-12. Available from:

https://doi.org/10.1016/j.ijnurstu.2018.06.012

\section{Supplementary Files}

This is a list of supplementary files associated with this preprint. Click to download.

- 2okAmendmentsBMCHSR.docx

- PermisTwibell.pdf

- Cuestionari.V01.19.pdf 